\title{
Hippocampal Inputs to Identified Neurons in an in vitro Slice Preparation of the Rat Nucleus Accumbens: Evidence for Feed-Forward Inhibition
}

\author{
Cyriel M. A. Pennartz ${ }^{a}$ and Stephen T. Kitai \\ Department of Anatomy and Neurobiology, University of Tennessee, Memphis, School of Medicine, Memphis, Tennessee \\ 38163
}

The aim of the present study was to analyze responses of nucleus accumbens neurons to stimulation of the fornix. The recorded neurons were labeled with biocytin and identified as medium spiny neurons. A large majority of cells generated a depolarizing postsynaptic potential in response to stimulation of the fornix. Using intracellular current injection, this depolarizing response was dissociated into an EPSP reversing at $-6 \pm 6 \mathrm{mV}$ and an IPSP reversing at $-71 \pm 4$ $\mathrm{mV}$. Both the EPSP and IPSP were abolished by 6-cyano-7nitroquinoxaline-2,3-dione. In addition, the IPSP was blocked by bicuculline and picrotoxin. The onset latency of the EPSP was constant in spite of varying stimulus intensities. In contrast, the onset latency of the IPSP increased with decreasing stimulus intensity. Notably, the stimulus threshold for evoking IPSPs was generally lower than for EPSPs. At stimulus intensities well above threshold, the IPSP onset was only slightly delayed with respect to the EPSP onset.

These results indicate that the EPSP can be characterized as a monosynaptic and glutamate-mediated synaptic response. The IPSP, however, appears to be mediated by a disynaptic feed-forward pathway involving both glutamate and GABA , receptors. Recurrent and lateral inhibitory interactions have previously been proposed to be predominant organizational principles in the caudate-putamen and nucleus accumbens. This study indlcates that feed-forward inhibition is an additional principle governing the activities of striatal neural networks.

The nucleus accumbens (Acb), which is the main component of the ventral striatum (Heimer and Wilson, 1975), is a point of focal interest among neuroscientists because of its involvement in behavioral reinforcement and in initiation of goal-directed behaviors (Mogenson et al., 1980; Fibiger and Phillips, 1988; Koob and Bloom, 1988). The Acb is densely innervated by afferents originating in the subiculum (Groenewegen et al., 1987). This projection is considered to subserve the transfer of

\footnotetext{
Received Dec. 10, 1990; revised Apr. 11, 1991; accepted Apr. 23, 1991.

We thank P. H. Boeijinga, H. T. Chang, H. J. Groenewegen, F. H. Lopes da Silva, N. J. de Vries, and J. Whittaker for their advice and comments on the manuscript. QX-314 was a generous gift from B. Takman and R. Sandberg (Astra Pharmaceuticals). This project was supported by USPHS Grants NS 23886 and 20702 (S.T.K.).

Correspondence should be addressed to $\mathrm{S}$. T. Kitai at the above address.

a Present address: Neurophysiology Division, Department of Experimental Zoology, University of Amsterdam, Kruislaan 320, 1098 SM, Amsterdam, Netherlands.
}

Copyright (c) 1991 Society for Neuroscience $0270-6474 / 91 / 112838-10 \$ 03.00 / 0$ contextual information relevant for undertaking motor actions (O'Keefe and Nadel, 1978; Mogenson et al., 1980; Scheel-Krüger and Willner, 1991). Biochemical and transmitter-specific tracing studies suggest that subicular afferents are, at least in part, glutamatergic (Walaas and Fonnum, 1980; Christie et al., 1987; Fuller et al., 1987). Studies of unit activity in in vivo preparations have revealed a variety of response patterns of Acb neurons following stimulation of the subiculum or fornix. The majority of units exhibited a transient excitatory or excitatoryinhibitory firing pattern. Some units, however, showed a transient decrease in spontaneous activity (Holland and Soedjono, 1981; Lopes da Silva et al., 1984; Yang and Mogenson, 1984; DeFrance et al., 1985; Hakan and Henriksen, 1989; Boeijinga et al., 1990). The major aim of this study was to unravel the functional circuits generating these responses by intracellular recordings in an in vitro slice preparation. Intracellular labeling was performed to identify the morphological phenotype of the recorded neurons.

Previously, investigators have emphasized the importance of lateral and recurrent inhibitory interactions between medium spiny neurons in the neostriatum (Park et al., 1980; Wilson and Groves, 1980; Katayama et al., 1981; Somogyi et al., 1981; Groves, 1983; Smith and Bolam, 1990). It has been suggested that lateral inhibition may subserve temporal and spatial filtering of inputs (Groves, 1983). The results presented here indicate the presence of a feed-forward inhibitory pathway that may operate in concert with lateral and recurrent circuits in the Acb.

\section{Materials and Methods}

Preparation. Slices were prepared from male Sprague-Dawley rats $(100-$ $180 \mathrm{gm}$ ) that had been anesthetized with ether. After decapitation, the brain was removed from the skull and cooled in Ringer's solution at 2$4^{\circ} \mathrm{C}$. Parasagittal slices of $500 \mu \mathrm{M}$ thickness were cut on a vibratome and transferred to a storage chamber. After $1 \mathrm{hr}$ rest, one of the slices was placed in a recording chamber and continuously superfused (1-2 $\mathrm{ml} / \mathrm{min})$ with oxygenated $\left(95 \% \mathrm{O}_{2}, 5 \% \mathrm{CO}_{2}\right)$ Ringer's solution $\left(32-34^{\circ} \mathrm{C}\right.$, $\mathrm{pH} 7.3$ ) of the following composition (in $\mathrm{mM}$ ): $\mathrm{NaCl}, 124 ; \mathrm{KCl}, 3.5$; $\mathrm{MgSO}_{4}, 1.0 ; \mathrm{CaCl}_{2}, 2.5 ; \mathrm{KH}_{2} \mathrm{PO}_{4}, 1.2 ; \mathrm{NaHCO}_{3}, 26.0 ;$ D-glucose, 10.0 .

Recording and stimulation. We used an interface-type recording chamber except for the pharmacological experiments, where slices were fully submerged. Electrical stimulation consisted of monopolar rectangular current pulses $(0.2 \mathrm{msec}$ duration, $0.1-0.2 \mathrm{~Hz})$ applied through two 60- $\mu \mathrm{m}$-thick stainless-steel electrodes, insulated except at the tip and separated by $100-200 \mu \mathrm{m}$. Responses to fornix stimulation were generally evoked at lower stimulus intensities in slices maintained in the interface chamber as compared to submerged slices. The values given below denote stimulus intensities used in the interface chamber. Stimulation electrodes were placed in the ventral part of the fornix. Intracellular recordings were made from the caudal part of the shell region of Acb, 0.6-1.1 mm lateral to the midline (cf. Paxinos and Wat- 


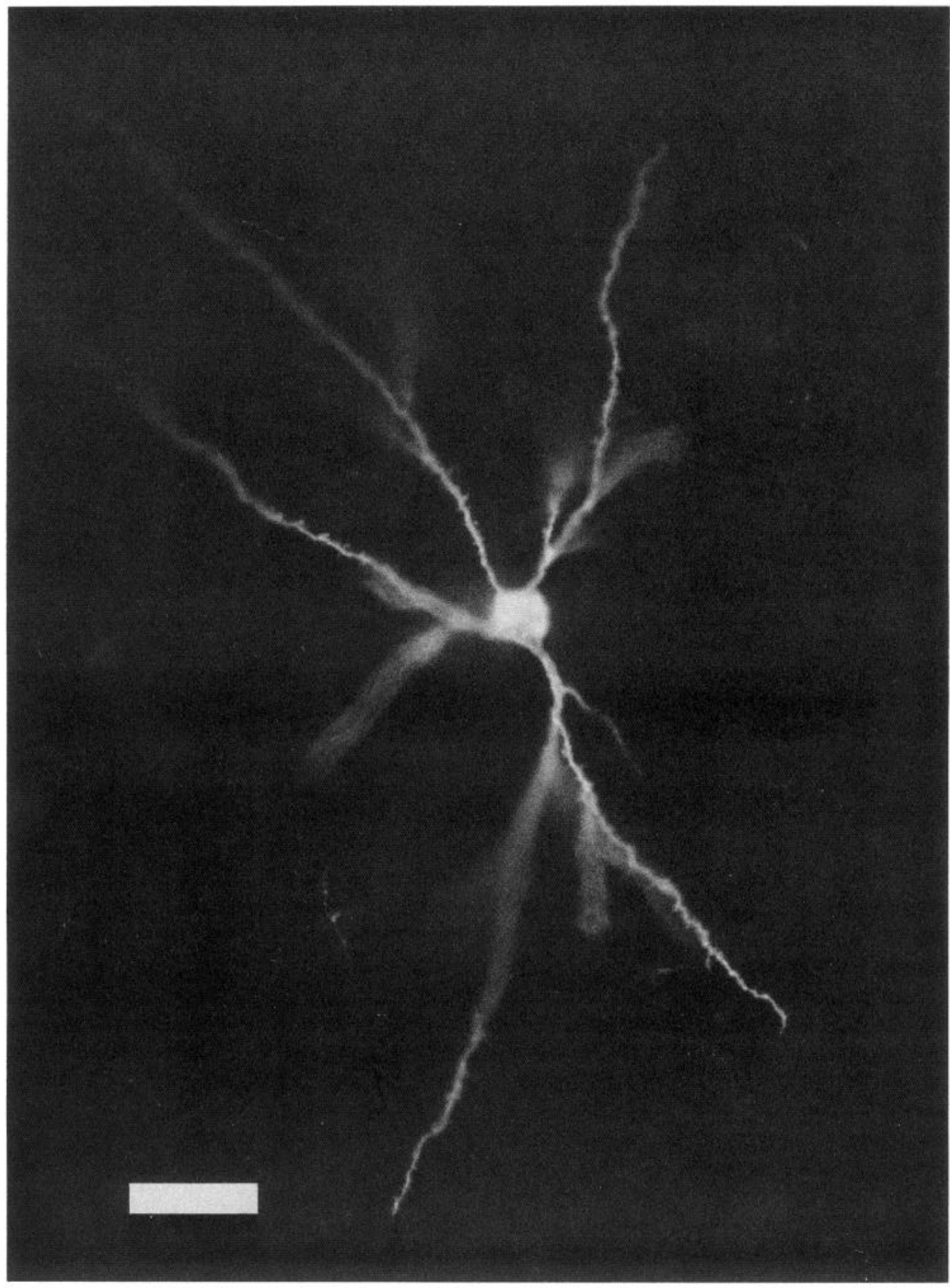

Figure 1. Example of a biocytin-labeled medium spiny neuron in the nucleus accumbens stained with avidinTexas Red. Scale bar, $50 \mu \mathrm{m}$. Fornix responses recorded from this neuron are shown in Figures 4 and 6.

son, 1986). Recording electrodes were glass micropipettes filled with $0.5 \mathrm{M} \mathrm{K}$-methylsulfate and $2 \%$ biocytin (pH 8.0, 80-150 M $\Omega$ ). Intracellular potentials were recorded using a Neurodata IR 183 amplifier (bandwidth, 0-1 MHz) and displayed on a Nicolet 206 oscilloscope. The recordings were stored on videotape for further analysis, and the membrane potential was continuously monitored on a chart recorder.

Drugs and statistics. In all experiments where synaptic responses were studied at depolarized membrane potentials, electrodes were filled with the solution mentioned above plus $100 \mathrm{~mm}$ QX-314, a lidocaine derivative that blocks action potentials when injected intracellularly (Connors and Prince, 1982). The bridge balance was regularly monitored in these experiments.

6-Cyano-7-nitroquinoxaline-2,3-dione (CNQX) was obtained from Tocris Neuramin; glycine and (-)-bicuculline methiodide were obtained from Sigma and QX-314 from Astra Pharmaceuticals (Worcester, MA).

Numerical values are expressed as mean \pm SEM. Statistical comparisons were made using Wilcoxon's matched-pairs signed rank test.

Histology. Biocytin (Sigma; cf. Horikawa and Armstrong, 1988) were injected intracellularly by passing negative current $(0.2-0.4 \mathrm{nA})$ through the recording electrode for at least $5 \mathrm{~min}$. Usually, only one or two cells were labeled per slice. Following termination of the experiment, the slice was stored in fixative ( $4 \%$ paraformaldehyde, $0.5 \%$ glutaraldehyde, $15 \%$ picric acid in $0.1 \mathrm{~m}$ sodium phosphate buffer, $\mathrm{pH} 7.4$ ). The slice was sectioned at a thickness of $40 \mu \mathrm{m}$ on a freezing microtome, collected into phosphate-buffered saline, and rinsed several times. Sections were incubated overnight in phosphate-buffered saline containing avidinTexas Red ${ }^{\mathrm{TM}}$ (Vector; dilution, $1: 100$ ), $0.3 \%$ Triton X-100, and $0.1 \%$ $\mathrm{NaN}_{3}$ and examined by fluorescent microscopy.

\section{Results}

\section{Membrane properties and morphology of recorded neurons}

Membrane properties were routinely monitored in all neurons investigated for responses to fornix stimulation $(N=52)$. They had a mean resting membrane potential (RMP) of $-71 \pm 1$ $\mathrm{mV}$; spontaneous activity was absent. The spike threshold, as estimated by injection of depolarizing current pulses, was -43 
A

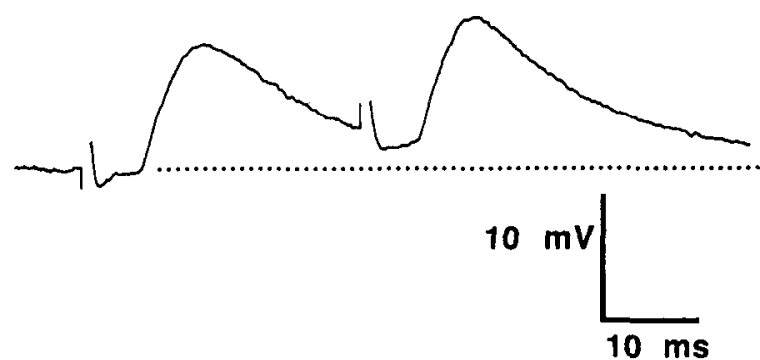

B

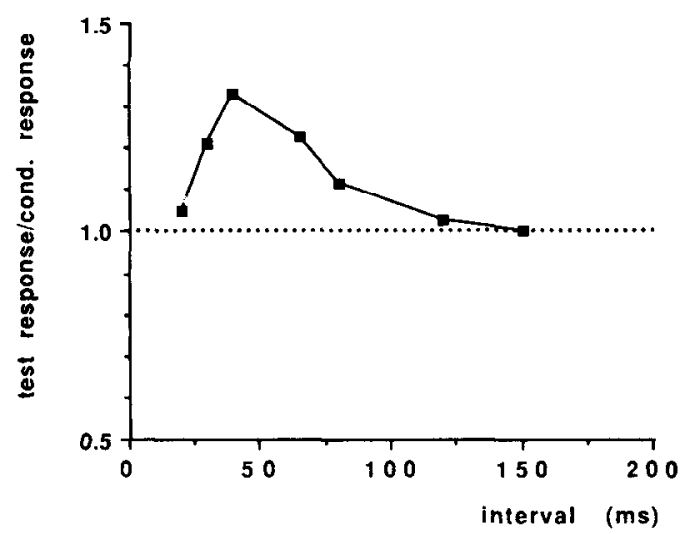

Figure 2. Paired-pulse facilitation of the fornix response. $A$, Using an interval of $30 \mathrm{msec}$, the test response was enhanced with respect to the conditioning response. $B$, The paired-pulse ratio (peak amplitude of test response/conditioning response) is plotted as a function of interstimulus interval. The resting membrane potential of this neuron was $-75 \mathrm{mV}$.

$\pm 2 \mathrm{mV}$. Action potential amplitude and duration were $85 \pm$ $3 \mathrm{mV}$ (measured from resting level) and $1.7 \pm 0.1 \mathrm{msec}$ (measured at the base), respectively. The input resistance and time constant, as estimated by injection of depolarizing current pulses $(0.1-0.3 \mathrm{nA}, 100-300 \mathrm{msec}$ duration), were $64 \pm 5 \mathrm{M} \Omega$ and 8.5 $\pm 0.9 \mathrm{msec}$, respectively. Regular spike trains exhibiting little frequency adaptation were elicited in response to strong depolarizing current pulses. Inward rectification in the hyperpolarizing direction was present in a majority of neurons (cf. Uchimura et al., 1989; Pennartz et al., 1991).

Twenty-three cells were sufficiently labeled to allow morphological identification. An example of a labeled neuron stained by avidin-Texas Red is shown in Figure 1. All labeled neurons were characterized by the presence of spines on their distal dendrites. Their somata were round, polygonal, or oval in shape; both somata and primary dendrites were devoid of spines. The average maximal soma diameter was $16 \pm 1 \mu \mathrm{m}$ (range, 9-24 $\mu \mathrm{m}$ ). The mean number of primary dendrites per cell was 3.9 \pm 0.2 . Axons originated from the soma or from one of the primary dendrites and branched profusely in the dendritic domain of the parent cell. Some of the axon collaterals could be traced into the ventral pallidum or subpallidal area.

\section{Response to fornix stimulation}

Stimulation of the ventral portion of the fornix bundle elicited a depolarizing postsynaptic potential (Fig. $2 A$ ) in 48 of 52 cells tested at RMP (in the remaining portion of cells, no response could be evoked). The onset latency and rise time of the response were $4.4 \pm 0.2$ and $4.5 \pm 0.3 \mathrm{msec}$, respectively. The half-decay time was $11.8 \pm 0.8 \mathrm{msec}$. In about half of the neurons, spikes were elicited at high stimulus intensities. The spike latency $(8.2$ $\pm 0.5 ; N=23$ ) was only slightly shorter than the peak latency of the postsynaptic potential $(8.9 \pm 0.3 \mathrm{msec})$. In each individual cell, the spike latency showed an average variability ("jitter") of $0.9 \pm 0.2 \mathrm{msec}(N=13)$. Moreover, the spike latency increased with decreasing stimulus intensities. Antidromically activated neurons may be expected to generate spikes having a constant latency, but these were in fact never observed. The quantified parameters of the fornix response are summarized in Table 1.

Two experiments were conducted to exclude the possibility that Acb neurons were excited by stimulated fibers located outside the fornix. First, stimulation in the latcral scptum or stria medullaris failed to evoke responses in the Acb. Second, no responses to fornix stimulation could be elicited after its ventral part had been cut.

In a recent in vivo study of fornix responses in the Acb, Boeijinga et al. (1990) demonstrated a marked paired-pulse facilitation that could last up to $450 \mathrm{msec}$. To examine whether the in vitro fornix pathway exhibits the same phenomenon, pairedpulse tests were conducted in 17 neurons. Facilitation of peak amplitudes of the postsynaptic potential was especially found when stimulus intensities well below spike threshold were used (Fig. 2A). Test responses were usually enhanced with respect to

Table 1. Properties of synaptic responses elicited by stimulation of the fornix

\begin{tabular}{llll} 
& Mean & SEM & $\begin{array}{l}\text { Number } \\
\text { of cells }\end{array}$ \\
\hline EPSP component & & & \\
Onset latency (msec) & 4.4 & 0.2 & 48 \\
Rise time (msec) & 4.5 & 0.3 & 48 \\
Half-decay time (msec) & 11.8 & 0.8 & 48 \\
$\quad$ Reversal potential (mV) & -6 & 6 & 7 \\
Spike parameters & & & \\
Spike latency (msec) & 8.2 & 0.5 & 23 \\
Spike jitter (msec) & 0.9 & 0.2 & 13 \\
IPSP component & & & \\
Onset latency (msec) & 6.7 & 0.3 & 16 \\
Rise time (msec) & 6.7 & 0.7 & 16 \\
Half-decay time (msec) & 25 & 3 & 6 \\
Reversal potential (mv) & -71 & 4 & \\
\hline
\end{tabular}




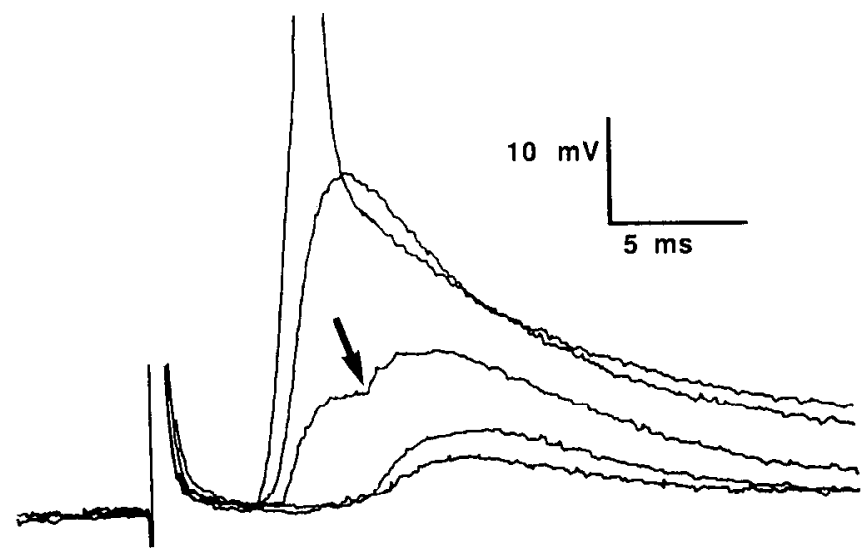

Figure 3. Input-output curve of the fornix response. At low stimulus intensities, a long-latency depolarizing postsynaptic potential was evoked. At intermediate intensities, a biphasic response was generated (onset of the late component is marked by an arrow). With progressively increasing intensities, the two depolarizing components fused into a large, short-latency depolarizing response, and finally a spike (truncated) was generated on top of the postsynaptic potential. Membrane potential was held at $-86 \mathrm{mV}$ by constant current injection. The RMP of this cell was $-69 \mathrm{mV}$.

conditioning responses across an interval range of 20-100 msec. In only two cells, facilitation occurred at intervals between 125 and $250 \mathrm{msec}$.

When cells were hyperpolarized below $-70 \mathrm{mV}$ and stimulated at low intensities (38 $\pm 7 \mu \mathrm{A})$, a depolarizing response was recorded whose onset latency was longer than the full-blown depolarizing postsynaptic potential evoked at high stimulus intensities (Fig. 3). At intermediate intensities $(88 \pm 18 \mu \mathrm{A})$, a biphasic postsynaptic potential was recorded in most neurons. This potential consisted of an early, high-threshold response and a late, low-threshold response, which was superimposed on the early response (Fig. 3, arrow). These components merged into one large depolarizing postsynaptic potential at high intensities $(174 \pm 20 \mu \mathrm{A})$.

To study the voltage dependence of the synaptic response in the absence of action potentials, electrodes filled with QX-314 were employed. Figure $4 A$ shows a typical example of a fornix response that was evoked at high stimulus intensities. It was composed of two components distinguished by different voltage dependencies. The early component was always depolarizing below approximately $0 \mathrm{mV}$ and monotonically decreased in amplitude when the cell was progressively depolarized with respect to resting level. The late component merged into a depolarizing postsynaptic potential with the early component at membrane potentials more negative than $-45 \mathrm{mV}$ but seemingly reversed its polarity above $-45 \mathrm{mV}$ (the estimated reversal potentials of these hyperpolarizing and depolarizing components studied in isolation are given below). In five cells, only the late, hyperpolarizing component of the fornix response could be evoked.

\section{Excitatory component of fornix response}

The early componcnt of the fornix response is considered to have an excitatory nature due to its near-zero reversal potential. In order to avoid contamination by the late, hyperpolarizing potential, this component was studied at about $-70 \mathrm{mV}$, cor-
A

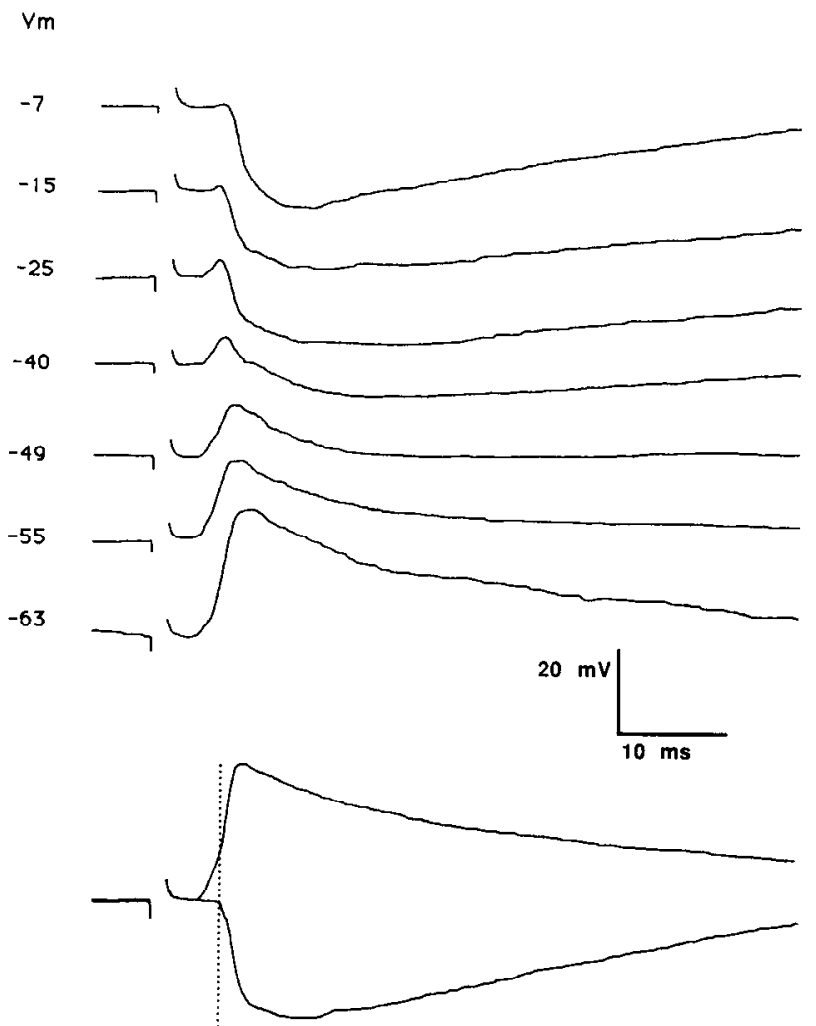

Figure 4. A, Voltage dependence of the fornix response. At membrane potentials more negative than $-45 \mathrm{mV}$, a depolarizing response was recorded. At membrane potentials depolarized to $-45 \mathrm{mV}$, a biphasic response emerged, consisting of an early depolarizing and a slightly delayed, hyperpolarizing component. $B$. The onset latency of the hyperpolarizing component, recorded at $-2 \mathrm{mV}$, was slightly longer than the onset latency of the depolarizing response, recorded at RMP. The onset of the hyperpolarizing component typically coincided with the mid-rising phase of the depolarizing response. $A$ and $B$ were recorded from the same medium spiny neuron (RMP, $-71 \mathrm{mV}$ ).

responding to the reversal potential of the hyperpolarizing potential (see below).

The quisqualate/kainate receptor antagonist CNQX (4-8 $\mu \mathrm{M})$ blocked the EPSP component (Fig. $5 A-C ; N=6$ ). To exclude side effects of CNQX on the glycine-binding site of the NMDA receptor complex, $30 \mu \mathrm{M}$ glycine was added to the drug solution in some experiments (cf. Harris and Miller, 1989; Thomson, 1989). Addition of this amino acid did not prevent the antagonistic action of CNQX.

The onset latency of the excitatory component (EPSP) was almost constant in spite of varying stimulus intensity (Figs. $6 \mathrm{~B}$, 7). Paired-pulse tests were performed to determine the refractory period of the EPSP. Stimulation sequences with intervals of 45 msec still elicited two separate EPSPs; with shorter intervals the test response merged into the conditioning response $(N=$ 7).

The excitatory component was modified after addition of the GABA $_{\mathrm{A}}$ antagonists bicuculline (30-60 $\mu \mathrm{M}, N=7$; Fig. $6 B$ ) and picrotoxin $(25 \mu \mathrm{M}, N=2)$. These $\mathrm{GABA}_{\mathrm{A}}$ antagonists prolonged and enhanced the EPSP. The latter effect was particularly clearly seen at low stimulation intensities.

The reversal potential of the EPSP, determined in the presence of bicuculline, was $-6 \pm 6 \mathrm{mV}(N=7)$. The relation between 
Figure 5. Effects of the quisqualate/ kainate receptor antagonist CNQX on the fornix response. Both the depolarizing $(A-C$, recorded at $-81 \mathrm{mV})$ and hyperpolarizing component $(D-F$, recorded at $-30 \mathrm{mV}$ ) were reversibly suppressed by $6 \mu_{\mathrm{M}} \mathrm{CNQX}$. Stimulus intensity was lowered in $D-F$ to avoid interference of the early, depolarizing response (cf. Fig. 7). The RMP of this neuron was $-81 \mathrm{mV}$.

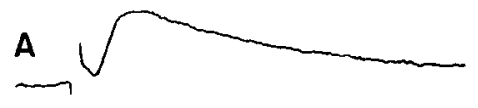

B
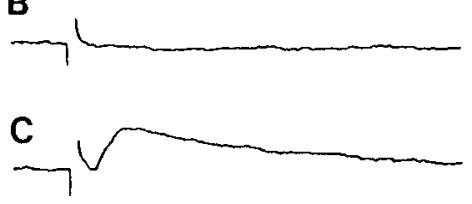

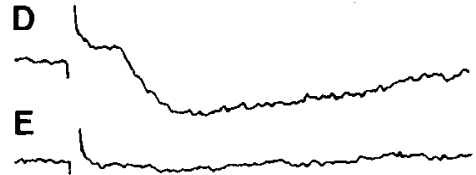

CONTROL 6 UM CNQX

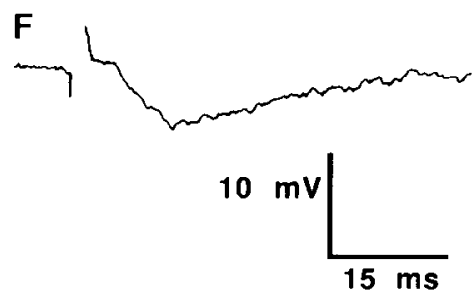

WASHOUT
EPSP peak amplitude and membrane potential was found to be nearly linear.

\section{Inhibitory component of fornix response}

The late, hyperpolarizing component could be most clearly studied during depolarization of the cell to $-30-0 \mathrm{mV}$. Its onset latency, rise, and half-decay time were $6.7 \pm 0.3,6.7 \pm 0.7$, and $25 \pm 3 \mathrm{msec}$, respectively $(N=16)$. This component was blocked by both bicuculline (30-60 $\mu \mathrm{M}, N=7$; Fig. $6 A$ ) and picrotoxin $(25 \mu \mathrm{M}, N=2)$ and can thus be identified as a $\mathrm{GABA}_{\mathrm{A}}$ receptor-mediated IPSP. Notably, 4-8 $\mu \mathrm{M}$ CNQX also abolished the IPSP (Fig. $5 D-F ; N=6$ ).

The temporal relation between the excitatory and inhibitory response components was studied in 15 neurons. The delay of IPSP onset with respect to EPSP onset was $2.3 \pm 0.3 \mathrm{msec}$. The onset latencies of both components were significantly correlated (linear regression, $p<0.01$ ). As shown in Figure $4 B$, the onset of the IPSP $(6.7+0.3 \mathrm{msec})$ was significantly shorter than the peak latency of the EPSP ( $8.9 \pm 0.3 \mathrm{msec} ; p<0.02 ; N=7$ ) and coincided with the mid-rising phase of the EPSP. The temporal distributions of EPSP onset latency, IPSP onset latency, and spike latency were all approximately unimodal (not shown).

The stimulus thresholds for evoking IPSPs and EPSPs were compared by examining the input-output curve of the fornix response at a membrane potential level where both components could be distinguished ( -30 to $-20 \mathrm{mV}$; Fig. 7). In all but 3 of 11 cells tested, it was found that the IPSP had a lower stimulus threshold than the EPSP (in the remaining three cells, the thresholds were almost equal). The difference in stimulus thresholds was exploited to determine the reversal potential of the IPSP. The peak amplitude of the IPSP depended on membrane potential in a nearly linear manner (Fig. 8); the reversal potential
Figure 6. Effects of the $\mathrm{GABA}_{\mathrm{A}}$ antagonist bicucullin on the fornix response. $A$, Application of $60 \mu \mathrm{M}$ bicuculline (Bic) abolished the hyperpolarizing component recorded at $-2 \mathrm{mV}$. $B$, In the left-hand panel, control responses were recorded at RMP using three different stimulus intensities. In the right-hand panel, the depolarizing responses were enhanced and prolonged following bicuculline application. The RMP of this medium spiny neuron was $-71 \mathrm{mV}$.
A

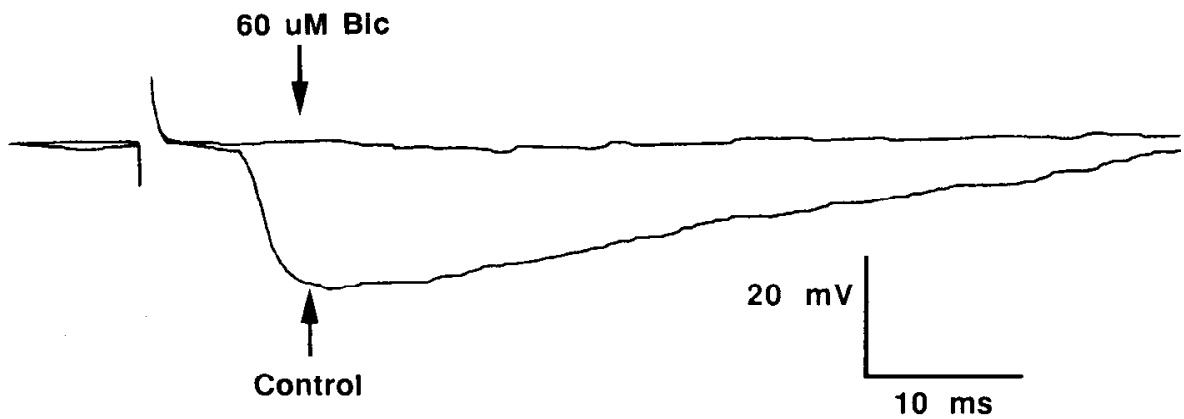

B

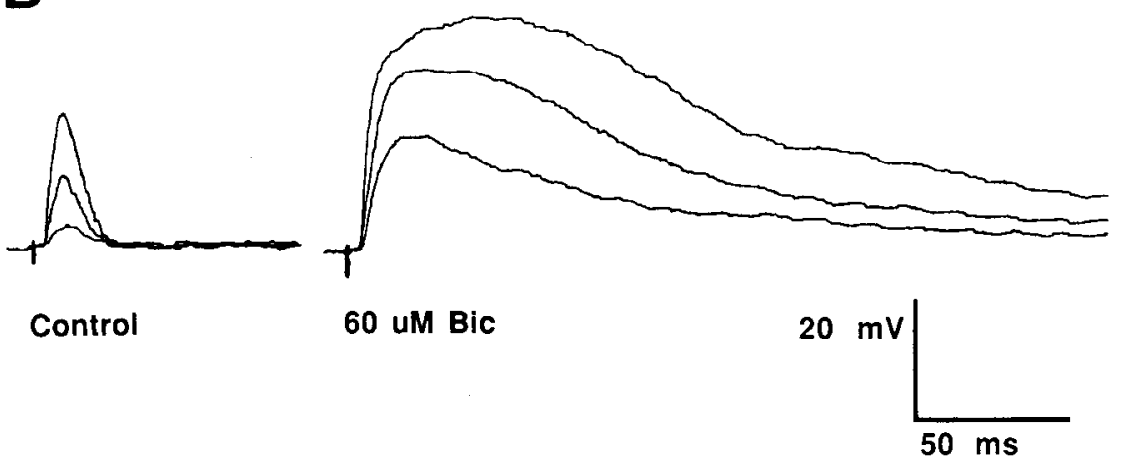




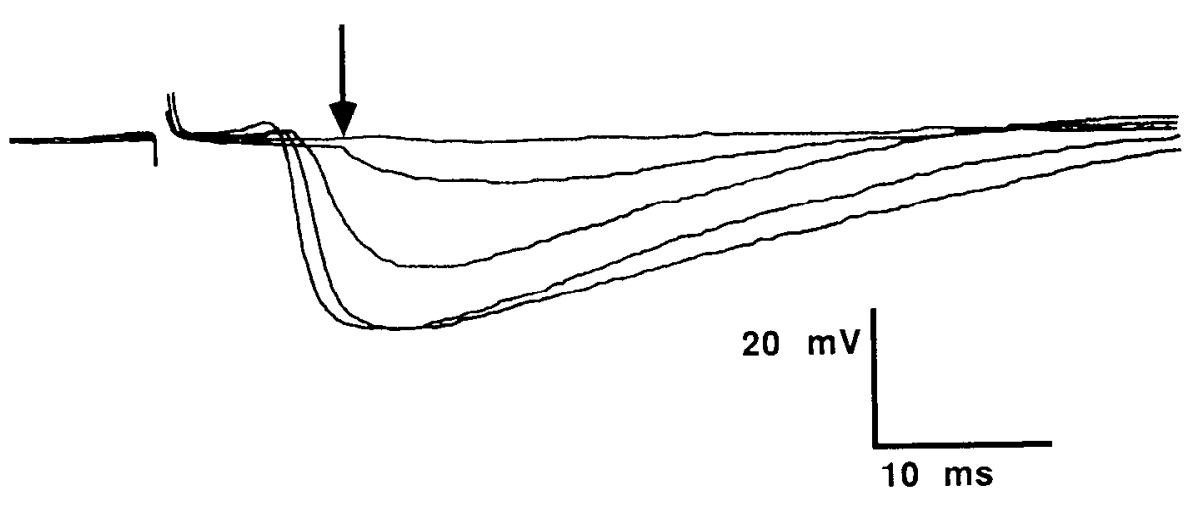

Figure 7. Input-output curve of the fornix response recorded at a membrane potential of $-20 \mathrm{mV}$. At high stimulus intensities, a biphasic depolarizing-hyperpolarizing (EPSP-IPSP) sequence was recorded. With progressively lower intensities, the amplitude of both the EPSP and IPSP component declined, but at the very lowest intensity, a small IPSP was still present (marked by arrow) while the EPSP disappeared. Furthermore, the IPSP onset exhibited a shift of several milliseconds, whereas the EPSP onset did not notably shift. The RMP of this medium spiny neuron was $-67 \mathrm{mV}$. was $-71 \pm 4 \mathrm{mV}(N=6)$. Using the same protocol, the late, low-threshold depolarizing component of the fornix response illustrated in Figure 3 was identified as a depolarizing IPSP.

Interestingly, the onset latency of the IPSP cxhibited a shift of $3.8 \pm 0.3 \mathrm{msec}$ when the stimulus intensity was varied between threshold (about $40 \mu \mathrm{A}$ ) and near-maximal (about 175 $\mu \mathrm{A}, N=9$; Fig. 7). In paired-pulse tests, the IPSP was found to have a refractory period of $7-10 \mathrm{msec}(N=7)$.

\section{Discussion}

Membrane properties and morphology of recorded neurons

All neurons labeled in this study were identified as medium spiny neurons, which are known to comprise the large majority of neurons encountered in the caudate-putamen and Acb (Wilson and Groves, 1980; Groves, 1983; Chang and Kitai, 1985; Smith and Bolam, 1990). In the Acb, these neurons project to the ventral pallidum, subpallidal area, and mesencephalon (Nauta et al., 1978; Groenewegen and Russchen, 1984; Chang and Kitai, 1985; Haber et al., 1990). The membrane properties described here resemble those recorded in medium spiny ncurons of the dorsal striatum (Kita et al., 1984; Kawaguchi et al., 1989), underscoring the physiological similarity of both regions (cf. Heimer and Wilson, 1975; Pennartz et al., 1990, 1991).

\section{Response to fornix stimulation}

The fornix bundle is known to contain efferents primarily from the subiculum and areas $\mathrm{CA} 1$ and $\mathrm{CA} 3$ of the hippocampus proper and various afferents to the hippocampal formation (Swanson et al., 1979; Lopes da Silva et al., 1990). Probably all of the descending fibers in the fornix originate in the hippocampal formation. It may therefore be assumed that the pathway studied here by fornix stimulation is indeed the CA1/subicular projection to the Acb as described by Heimer and Wilson (1975), Kelley and Domesick (1982), and Groenewegen et al. (1987). There is a slight possibility, however, that some efferent fibers from the entorhinal cortex could project to the medial Acb by way of the fornix.

Responses to fornix stimulation were shown to contain an early EPSP and a slightly delayed IPSP. Judging from the virtually fixed onset latency of the EPSP in spite of varying stimulus intensity and the small variability in latency of spikes, this component can be characterized as monosynaptic (cf. Pennartz et al., 1990). This finding confirms recent anatomical evidence favoring direct synaptic contacts between hippocampal afferents and glutamate decarboxylase-immunoreactive spiny neurons in the Acb (Meredith et al., 1990). The conduction velocity of the fornix fibers, calculated from the average EPSP onset latency, was $0.9 \mathrm{msec}$, which is in agreement with an in vivo study by Boeijinga et al. (1990).

CNQX blocked the EPSP in micromolar concentrations, indicating the chief involvement of glutamate receptors in mediating the excitatory inputs (Honoré et al., 1988; Pennartz et al., 1991). Addition of glycine to medium containing CNQX did not prevent the blocking effect of CNQX, suggesting that the suppression cannot be ascribed to an antagonistic action at the glycine binding site of the NMDA receptor complex (cf. Harris and Miller, 1989; Thomson, 1989). Thus, it can be concluded that quisqualate/kainate receptors substantially contribute to the EPSP. The reversal potential of the EPSP, as determined by current-clamp technique, was $-6 \pm 6 \mathrm{mV}$. The estimation of a reversal potential by injection of DC currents may, in principle, suffer from isopotentiality problems. Nonetheless, the value found here is in close agreement with the reversal potentials of quisqualate/kainate receptor-mediated responses reported in other preparations where low-resistance clcctrodes were used in the patch-clamp and voltage-clamp recording mode (Mayer and Westbrook, 1984; Ascher and Nowak, 1988; Cull-Candy et al., 1988; Hestrin et al., 1990).

When comparing the present intracellular findings with studies of unit activity in in vivo preparations, it is interesting to note that the diversity encountered in fornix responses in vivo is not directly reflected by the uniform EPSP-IPSP sequence found in most neurons tested here. The response pattern most commonly found following fornix stimulation in vivo is a shortlasting excitation. Some neurons exhibit an excitatory-inhibitory sequence, and a third pattern consists of mere inhibition (Holland and Soedjono, 1981; Lopes da Silva et al., 1984; Yang and Mogenson, 1984; DeFrance et al., 1985; Hakan and Henriksen, 1989; Boeijinga et al., 1990). The excitatory-inhibitory response pattern is clearly in agreement with the findings presented here. The occurrence of purely inhibitory responses may bc cxplained by the finding that the IPSP can be elicited at lower stimulus intensities than the EPSP (Fig. 7). In the face of the uniform EPSP-IPSP sequence reported here, the frequent occurrence of purely excitatory responses in vivo may seem puzzling. However, many ventral striatal neurons are not spontaneously active (Holland and Soedjono, 1981; Yang and Mogenson, 1984; DeFrance et al., 1985; Hakan and Henriksen, 1989; Boeijinga et al., 1990), and this condition is necessary to assess the presence of inhibition. For those units showing both spontaneous activity and purely excitatory fornix responses, our study cannot provide any direct intracellular correlate. 


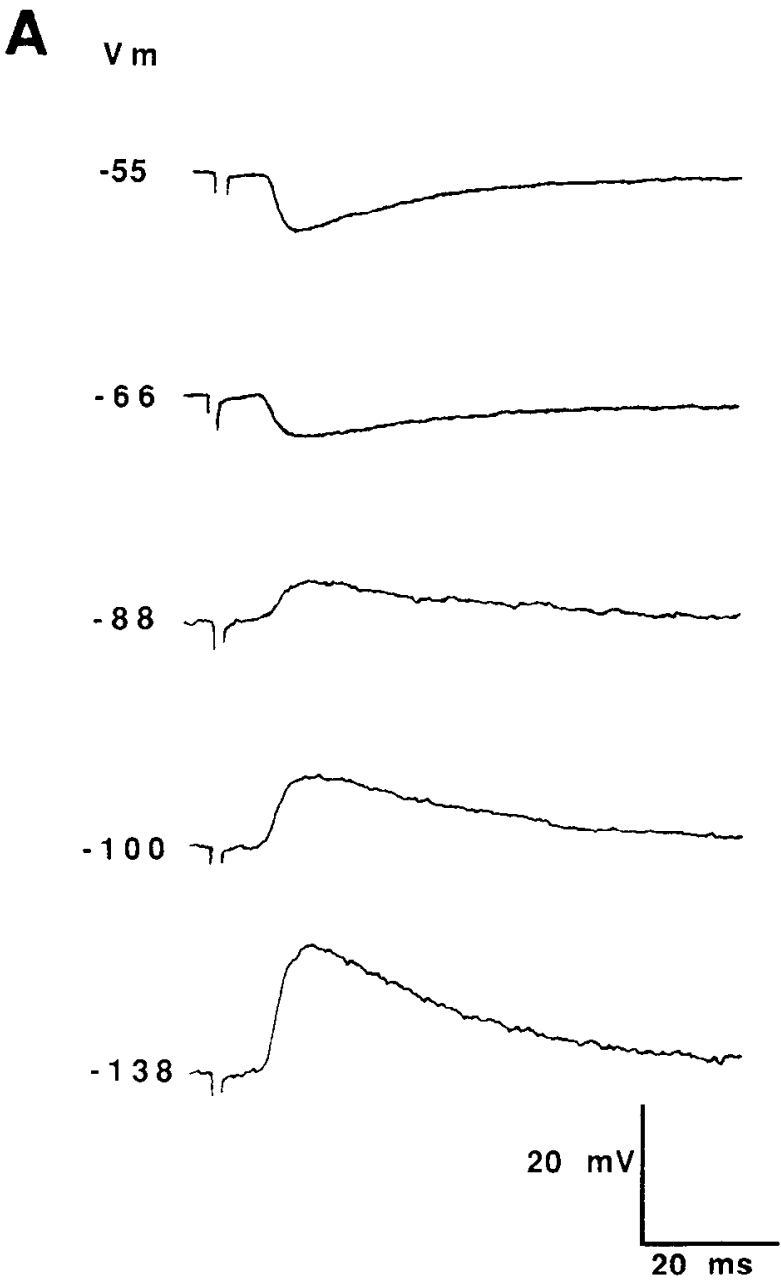

B

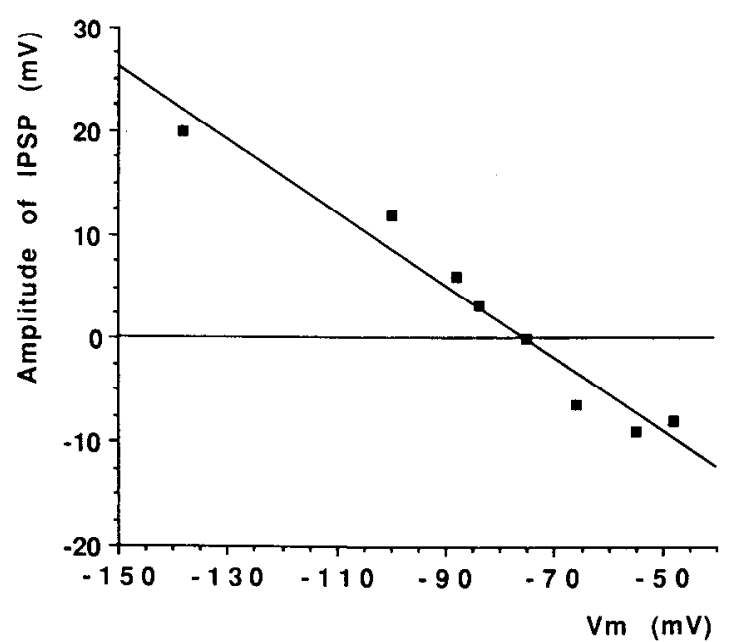

Figure 8. Determination of the reversal potential of the IPSP. $A$, Using low stimulus intensities, the fornix response was recorded at different membrane potentials and found to be monophasic at hyperpolarized as well as depolarized levels. $B$, The peak amplitude of the IPSP is plotted as a function of membrane potential. The IPSP depended in a nearly linear fashion on membrane potential and reversed its polarity at -75 $\mathrm{mV}$ in this neuron. The RMP of this cell was $-65 \mathrm{mV}$.
A
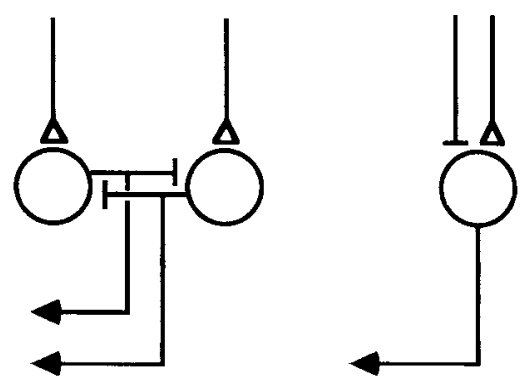

B

C

Figure 9. Diagrams illustrating local circuits possibly underlying fornix responses. $A$, In the case of lateral inhibition, medium spiny neurons receive monosynaptic excitatory inputs from the subiculum/CAl area (indicated by triangular synapses). The cells have axons projecting outside the Acb (illustrated by arrows), but in addition axon collaterals inhibit adjacent medium spiny neurons (indicated by flat synapses). Note that in these generalized schemes dendrites and spines have been left out. $B$, The monosynaptic inhibitory circuit consists of parallel excitatory and inhibitory inputs to the same medium spiny neuron. $C$, In the feed-forward inhibitory circuit, a medium spiny neuron receives a monosynaptic excitatory fornix input. Furthermore, fornix inputs monosynaptically excite an additional type of neuron (small circle) that inhibits the medium spiny neuron. In $B$ and $C$, axon collaterals do not play a role in mediating the IPSP and have been left out for simplicity.

Fornix responses studied in vitro usually cxhibited paircdpulse facilitation at intervals between 20 and $100 \mathrm{msec}$ (Fig. $2 B$ ). It should be noted that part of the facilitation effect may be explained by temporal summation of the test and conditioning response, since the onset of the test response overlaps the tail of the conditioning response (Fig. 2A). Fornix responses recorded in vivo exhibit facilitation at longer intervals (up to 450 msec; Boeijinga et al., 1990) than in vitro. One of the possible explanations of this difference is that fornix stimulation in vivo is likely to activate a hippocampal/subicular loop by antidromic activation of projection fibers in the fornix (P. H. Boeijinga, A. B. Mulder, C. M. A. Pennartz, and F. H. Lopes da Silva, unpublished observations). The ensuing secondary volley reaches the Acb after the primary volley and may prolong the facilitation effect.

\section{Circuit analysis}

The delayed, hyperpolarizing component of the fornix response reversed its polarity at $-71+4 \mathrm{mV}$ and was blocked by bicuculline and picrotoxin, indicating that this component can be identified as a $\mathrm{GABA}_{\mathrm{A}}$ receptor-mediated IPSP. It is worthwhile to note that a different value of the IPSP reversal potential is found when it is not studied in isolation (as in Fig. 8) but in the presence of a preceding EPSP. In the latter case, an approximate reversal potential of $-45 \mathrm{mV}$ is found (Fig. $4 A$ ). Uchimura et al. (1989) also determined the IPSP reversal potential in the presence of an EPSP and found a similar value $(-35 \mathrm{mV})$. Since the EPSP extends well into the time domain of the IPSP (Fig. $4 B$ ), it is likely to obscure the voltage dependence of the pure IPSP. Therefore, experiments studying the IPSP at subthreshold stimulus intensities for the EPSP are likely to provide a better estimate of the IPSP reversal potential.

The IPSP component may be explained by several mechanisms. In all of the hypothetical circuit diagrams considered 
here, medium spiny neurons are proposed to be monosynaptically excited by fornix fibers. First, the IPSP recorded in these cells could arise from activation of axon collaterals originating in neighboring spiny neurons (Fig. $9 \mathrm{~A}$, lateral inhibition) or from activation of collaterals making synaptic contacts onto the parent cell itself (autaptic recurrent inhibition). Second, the fornix may contain both excitatory and inhibitory fibers making monosynaptic contacts with medium spiny neurons (Fig. 9B). Third, a feed-forward inhibitory circuit may explain our observations. In this circuit, an interneuron receives excitatory fornix inputs and projects to the medium spiny neuron (Fig. 9C).

Several experiments indicate that the IPSP cannot be mediated by lateral or autaptic recurrent inhibition. IPSPs could still be evoked in neurons whose action potentials were blocked by QX-314 (Figs. 4-8), a finding that excludes the possibility of autaptic recurrent inhibition. Both lateral and autaptic recurrent inhibition predict that the average onset latency of the IPSP should be longer than the average spike latency. If anything, however, the mean onset latency of the IPSP was shorter than the spike latency in our recordings (Table 1). Moreover, the onset latency of the IPSP was significantly shorter than the peak latency of the FPSP (Fig. 4B). As noted above, spikes were consistently generated on top of the EPSP, not in its rising phase. Another implication of autaptic recurrent and lateral inhibitory circuits is that the stimulus threshold for evoking an IPSP should be clearly larger than for evoking an EPSP. In contrast, the IPSP was usually found to have a lower stimulus threshold than the EPSP.

An alternative recurrent-inhibitory circuit, which would not be contradicted by findings concerning timing and stimulus threshold for the IPSP with respect to the EPSP, may be envisaged as follows. Electrical stimulation of the fornix could cause antidromic activation of ascending axon collaterals of medium spiny neurons along with descending glutamatergic $\mathrm{f}$ bers. The axon collaterals might synapse on interneurons as in Figure $9 C$ and thus elicit a disynaptic IPSP. This alternative can be rejected on other grounds than those mentioned above: (1) spikes elicited by antidromic activation of the collaterals would also invade the soma but were never observed in neurons not filled with QX-314 $(N=30)$; (2) medium spiny neurons are likely to contain GABA and several peptides (i.e., substance $P$, enkephalins, and dynorphin; DiFiglia et al., 1982; Vincent et al., 1982; Penny et al., 1986; Kita and Kitai, 1988; Pickel et al., 1988; Chesselet and Robbins, 1989; Smith and Bolam, 1990) as transmitters, which contradicts our finding that a quisqualate/ kainate receptor antagonist blocked the IPSP; and (3) despite extensive anatomical tracing studies, it has never been documented in the anatomical literature that the Acb would send projection fibers to the hippocampal formation or to any other brain area by way of the fornix (Swanson and Cowan, 1975; Nauta et al., 1978; Kelley and Domesick, 1982; Groenewegen and Russchen, 1984; Haber et al., 1990). Thus, it can be concluded that lateral or autaptic recurrent inhibitory circuits cannot account for our observations.

Three indications were found against a circuit implying monosynaptic inhibition. In a monosynaptic response, the onset latency is required to be approximately constant with varying stimulus intensity. The onset latency of the IPSP, however, exhibited a considerable shift (Fig. 7). Second, if the glutamatergic and GABAergic afferents to medium spiny neurons are assumed to function separately, it would follow that the former transmitter system can be antagonized without blocking the latter. In contrast, CNQX was found to block the IPSP. This antagonism cannot be explained by a nonspecific binding of CNQX to $\mathrm{GABA}_{\mathrm{A}}$ receptors since the corresponding $\mathrm{IC}_{50}$ excccds $25 \mu \mathrm{M}$ (Honoré et al., 1988). Finally, high-frequency following tests of the EPSP and IPSP yielded estimated refractory periods of 4-5 and 7-10 msec, respectively. While a circuit of parallel monosynaptic excitatory and inhibitory inputs would predict approximately the same values for these periods, the difference we found is consistent with feed-forward inhibition.

Although we have no direct evidence for identifying the location and morphological phenotype of the neuronal element mediating feed-forward inhibition, some suggestions can be made. The fornix is known to project to lateral septal neurons, but these neurons are unlikely to mediate the IPSP found in medium spiny Acb neurons because, first, stimulation of the lateral septum does not evoke IPSPs in the neurons studied here and, second, no anatomical indications have been obtained for a projection from the septum to the Acb (Swanson and Cowan, 1979). The origin of the IPSP is most probably located within the Acb itself since local stimulation evokcs a very similar type of IPSP that is also mediated by $\mathrm{GABA}_{\mathrm{A}}$ receptors (Uchimura et al., 1989; Pennartz et al., 1991).

According to the circuit sketched in Figure $9 C$, an interneuron is assumed to mediate the feed-forward inhibition. Another possibility, however, is that there are two classes of medium spiny neurons, one of which inhibits the other in a feed-forward fashion. Although the latter possibility cannot entirely be excluded, two findings suggest that this proposal is unlikely: (1) the sum of EPSP rise time plus spike duration measured in medium spiny neurons $(6.2 \mathrm{msec})$ is much longer than the average delay of IPSP onset with respect to EPSP onset $(2.3 \mathrm{msec}$; Table 1); (2) medium spiny neurons responded to fornix stimulation in a homogeneous fashion: unimodal distributions of spike thresholds, EPSP onset latencies, IPSP onset latencies, and spike latencies were found. Thus, the results favor the involvement of an additional type of neuron. A likcly candidate for mediating the feed-forward IPSP would be the mediumsized, aspiny GABAergic interneuron. This neuron is parvalbumin positive, receives asymmetrical synaptic contacts, and synapses extensively onto medium spiny neurons (Bolam et al., 1983; Kita et al., 1989; Smith and Bolam, 1990).

In the dorsal striatum, results obtained by various groups suggest the presence of lateral and autaptic recurrent inhibition onto medium spiny neurons (Park et al., 1980; Wilson and Groves, 1980; Katayama et al., 1981; Somogyi et al., 1981; Groves, 1983; Smith and Bolam, 1990). Recently, Wilson et al. (1989) also found some indications for feed-forward inhibition in the corticostriatal pathway. In the ventral striatum, no evidence has yet been presented for lateral or recurrent IPSPs existing alongside feed-forward IPSPs. Although this type of inhibition is apparently not elicited by fornix stimulation, we cannot exclude activation of lateral or recurrent circuits by other pathways.

In summary, medium spiny neurons in the Acb generate an EPSP/IPSP sequence in response to stimulation of the fornix. The initial excitatory component is rapidly followed by a precisely timed inhibitory component. The two components appear to be mediated by quisqualate/kainate receptors and $\mathrm{GABA}_{\mathrm{A}}$ receptors, respectively. Whereas the EPSP can be interpreted as a monosynaptic response, the IPSP is most probably relayed by an interneuron located within the ventral striatum. This relay will put temporal constraints on incoming excitatory signals. 
The feed-forward IPSP will effectively limit the duration of the excitatory signal and the number of action potentials generated. The transient signaling mode resulting from this type of circuitry may have important consequences for the functioning of basal forebrain mechanisms crucial for processing limbic inputs and initiating motor activities.

\section{References}

Ascher P, Nowak L (1988) Quisqualate- and kainate-activated channels in mouse central neurones in culture. J Physiol (Lond) 399:227245.

Boeijinga PH, Pennartz CMA, Lopes da Silva FH (1990) Paired-pulse facilitation in the nucleus accumbens following stimulation of subicular inputs in the rat. Neuroscience 35:301-311.

Bolam JP, Clarke DJ, Smith AD, Somogyi P (1983) A type of aspiny neuron in the rat neostriatum accumulates [ ${ }^{3} \mathrm{H}$ ]gamma-aminobutyric acid: combination of Golgi-staining, autoradiography and electron microscopy. J Comp Neurol 213:121-134.

Chang HT, Kitai ST (1985) Projection neurons of the nucleus accumbens: an intracellular labeling study. Brain Res 347:112-116.

Chesselet MF, Robbins F (1989) Characterization of striatal neurons expressing high levels of glutamic acid decarboxylase messenger RNA. Brain Res 492:237-244.

Christie MJ, Summers RJ, Stephenson JA, Cook CJ, Beart PM (1987) Excitatory amino acid projections to the nucleus accumbens septi in the rat: a retrograde transport study utilizing $\mathrm{D}\left[{ }^{3} \mathrm{H}\right]$ aspartate and $\left[{ }^{3} \mathrm{H}\right] \mathrm{GABA}$. Neuroscience 22:425-439.

Connors BW, Prince DA (1982) Effects of local anesthetic QX-314 on the membrane properties of hippocampal pyramidal neurons. $J$ Pharmacol Exp Ther 220:476-481.

Cull-Candy SG, Howe JR, Ogden DC (1988) Noise and single channels activated by excitatory amino acids in rat cerebellar granule neurones. J Physiol (Lond) 400:189-222.

DeFrance JF, Marchand JF, Sikes RW, Chronister RB, Hubbard JI (1985) Characterization of fimbria input to nucleus accumbens. J Neurophysiol 54:1553-1567.

DiFiglia M, Aronin N, Martin JB (1982) Light and electron microscopic localization of immunoreactive Leu-enkephalin in the monkey basal ganglia. J Neurosci 2:303-320.

Fibiger HC, Phillips AG (1988) Mesocorticolimbic dopamine systems and reward. Ann NY Acad Sci 537:206-215.

Fuller TA, Russchen FT, Price JL (1987) Sources of presumptive glutamergic/aspartergic afferents to the rat ventral striatopallidal region. J Comp Neurol 258:317-338.

Groenewegen HJ, Russchen FT (1984) Organization of the efferent projections of the nucleus accumbens to pallidal, hypothalamic and mesencephalic structures: a tracing and immunohistochemical study in the cat. J Comp Neurol 223:347-367.

Groenewegen HJ, Vermeulen-Van der Zee E, te Kortschot A, Witter MP (1987) Organization of the projections from the subiculum to the ventral striatum in the rat. A study using anterograde transport of Phaseolus vulgaris leucoagglutinin. Neuroscience 23:103-120.

Groves PM (1983) A theory of the functional organization of the neostriatum and the neostriatal control of voluntary movement. Brain Res Rev 5:109-132.

Haber SN, Lynd E, Klein C, Groenewegen HJ (1990) Topographic organization of the ventral striatal efferent projections in the rhesus monkey: an anterograde tracing study. J Comp Neurol 293:282-298.

Hakan RL, Henriksen SJ (1989) Opiate influences on nucleus accumbens neuronal electrophysiology: dopamine and non-dopamine mechanisms. J Neurosci 9:3538-3546.

Harris KM, Miller RJ (1989) CNQX (6-cyano-7-nitroquinoxaline2,3-dione) antagonizes NMDA-evoked $\left[{ }^{3} \mathrm{H}\right] \mathrm{GABA}$ release from cultured cortical neurons via an inhibitory action at the strychnineinsensitive glycine site. Brain Res 489:185-189.

Heimer L, Wilson RD (1975) The subcortical projections of the allocortex: similarities in the neural associations of the hippocampus, the prepyriform cortex and the neocortex. In: Perspectives in neurobiology. Golgi centennial symposium (Santini M, ed), pp 177-193. New York: Raven.

Hestrin S, Nicoll RA, Perkel DJ, Sah P (1990) Analysis of excitatory synaptic action in pyramidal cells using whole-cell recording from rat hippocampal slices. J Physiol (Lond) 422:203-225.
Holland RC, Soedjono A (1981) Electrophysiological studies of the nucleus accumbens. In: The neurobiology of the nucleus accumbens (Chronister RB, DeFrance JF, eds), pp 253-258. Brunswick, ME: Haer Institute.

Honoré T, Davies SN, Drejer J, Fletcher EJ, Jacobsen P, Lodge D, Nielsen FE (1988) Quinoxalinediones: potent competitive nonNMDA glutamate receptor antagonists. Science 241:701-703.

Horikawa K, Armstrong WE (1988) A versatile means of intracellular labeling: injection of biocytin and its detection with avidin conjugates. J Neurosci Methods 25:1-11.

Katayama Y, Miyazaki S, Tsubokawa T (1981) Electrophysiological evidence favoring in tracaudate axon collaterals of GABAergic caudate output neurons in the cat. Brain Res 216:180-186.

Kawaguchi Y, Wilson CJ, Emson PC (1989) Intracellular recording of identified neostriatal patch and matrix spiny cells in a slice preparation preserving cortical inputs. J Neurophysiol 62:1052-1068.

Kelley AE, Domesick VB (1982) The distribution of the projection from the hippocampal formation to the nucleus accumbens in the rat: an anterograde- and retrograde-horseradish peroxidase study. Neuroscience 7:2321-2335.

Kita H, Kitai ST (1988) Glutamate decarboxylase immunoreactive neurons in rat neostriatum: their morphological types and populations. Brain Res 447:346-352.

Kita H, Kosaka T, Heizmann CW (1989) The morphology of parvalbumin immunoreactive neurons in the rat neostriatum. Soc Neurosci Abstr 15:907.

Kita T, Kita II, Kitai ST (1984) Passive electrical membrane properties of rat neostriatal neurons in an in vitro slice preparation. Brain Res 300:129-139.

Koob GF, Bloom FE (1988) Cellular and molecular mechanisms of drug dependence. Science 242:715-723.

Lopes da Silva FH, Arnolds DEAT, Neijt HC (1984) A functional link between the limbic cortex and ventral striatum: physiology of the subiculum accumbens pathway. Exp Brain Res 55:205-214.

Lopes da Silva FH, Witter MP, Boeijinga PH, Lohman AHM (1990) Anatomic organization and physiology of the limbic cortex. Physiol Rev 70:453-511.

Mayer ML, Westbrook GL (1984) Mixed-agonist action of excitatory amino acids on mouse spinal cord neurones under voltage clamp. J Physiol (Lond) 354:29-53.

Meredith GE, Wouterlood FG, Pattiselanno A (1990) Hippocampal fibers make synaptic contacts with glutamate decarboxylase-immunoreactive neurons in the rat nucleus accumbens. Brain Res 513:329334.

Mogenson GJ, Jones DL, Yim CY (1980) From motivation to action: functional interface between the limbic system and the motor system. Prog Neurobiol 14:69-97.

Nauta WJH, Smith GP, Faull RLM, Domesick VB (1978) Efferent connections and nigral afferents of the nucleus accumbens septi in the rat. Neuroscience 3:385-401.

O'Keefe J, Nadel L (1978) The hippocampus as a cognitive map. Oxford: Clarendon.

Park MR, Lighthall JW, Kitai ST (1980) Recurrent inhibition in the rat neostriatum. Brain Res 194:359-369.

Paxinos G, Watson C (1986) The rat brain in stereotaxic coordinates. New York: Academic.

Pennartz CMA, Boeijinga PH, Lopes da Silva FH (1990) Locally evoked potentials in slices of the rat nucleus accumbens: NMDA and non-NMDA receptor mediated components and modulation by GABA. Brain Res 529:30-41.

Pennartz CMA, Boeijinga PH, Lopes da Silva FH (1991) Intracellular recordings in slices of the rat nucleus accumbens: contribution of NMDA receptors to postsynaptic potentials and paired-pulse facilitation. Exp Brain Res, in press.

Penny GR, Afsharpour S, Kitai ST (1986) The glutamate decarboxylase-, leucine enkephalin-, methionine enkephalin-, and substance P-immunoreactive neurons in the neostriatum of the rat and cat: evidence for partial population overlap. Neuroscience 17:101 1-1045.

Pickel VM, Towle AC, Joh TH, Chan J (1988) Gamma-aminobutyric acid in the medial rat nucleus accumbens: ultrastructural localization in neurons receiving monosynaptic input from catecholaminergic afferents. J Comp Neurol 272:1-14.

Scheel-Krüger J, Willner P (1991) The mesolimbic system: principles of operation. In: The mesolimbic dopamine system: from motivation to action (Willner P, Scheel-Krüger J, eds), in press. New York: Wiley. 
Smith AD, Bolam JP (1990) The neural network of the basal ganglia as revealed by the study of synaptic connections of identified neurons. Trends Neurosci 13:259-265.

Somogyi P, Bolam JP, Smith AD (1981) Monosynaptic cortical input and local axon collaterals of identified striatonigral neurons. A light and electron microscopic study using the Golgi-peroxidase transportdegeneration procedure. J Comp Neurol 195:567-584.

Swanson LW, Cowan WM (1975) A note on the connections and development of the nucleus accumbens. Brain Res 92:324-330.

Swanson LW, Cowan WM (1979) The connections of the septal region in the rat. J Comp Neurol 186:621-655.

Thomson AM (1989) Glycine modulation of the NMDA receptor/ channel complex. Trends Neurosci 12:349-353.

Uchimura N, Higashi H, Nishi S (1989) Membrane properties and synaptic responses of the guinea pig nucleus accumbens neurons in vitro. J Neurophysiol 61:769-779.

Vincent SR, Hokfelt T, Christensson I, Terenius L (1982) Immuno- histochemical evidence for a dynorphin immunoreactive striatonigral pathway. Eur J Pharmacol 85:251-252.

Walaas I, Fonnum F (1980) Biochemical evidence for glutamate as a transmitter in hippocampal efferents to the basal forebrain and hypothalamus in the rat brain. Neuroscience 5:1691-1698.

Wilson CJ, Groves PM (1980) Fine structure and synaptic connections of the common spiny neuron of the rat neostriatum: a study employing intracellular injection of horseradish peroxidase. J Comp Neurol 194: 599-615.

Wilson CJ, Kita H, Kawaguchi Y (1989) GABAergic interneurons, rather than spiny cell axon collaterals, are responsible for the IPSP responses to afferent stimulation in neostriatal spiny neurons. Soc Neurosci Abstr 15:907.

Yang CR, Mogenson GJ (1984) Electrophysiological responses of neurones in the nucleus accumbens to hippocampal stimulation and the attenuation of the excitatory responses by the mesolimbic dopaminergic system. Brain Res 324:69-84. 